Chemical Engineering Research Bulletin 17(2015) 34-39

\title{
PREDICTION OF URANIUM CONCENTRATION PROFILES ALONG A CONTINUOUS EXTRACTION COLUMN
}

\author{
Naima Khleifia*, Hamdi Rania and Ahmed Hannachi \\ Lobratory of Chemical Engineering and Industrial Systems, National Engineering School of Gabes, Omar Ibn \\ Elkhattab Street, Zrig Gabes 6029, University of Gabes, Tunisia
}

Received 25 December 2013; received in revised form 24 March 2015

\begin{abstract}
The increased growth in energy demand has a direct impact on the growing interest of uranium extraction. Phosphoric acid attracts a great attention because of its uranium content. The solvent extraction is the most widely used techniques for uranium separation from phosphoric acid. In the present work, the simulation of the uranium extraction along a continuous counter current column has been conducted. A computer code that accounts for mass balances and equilibrium data has been developed. The performed simulations allow to obtain the concentration profiles of uranium along the extraction column and led to assess the effect of operating conditions on the extraction performances.
\end{abstract}

Keywords: Continuous Colum; Simulation; Solvent Extraction; Uranium; Phosphoric Acid.

Available online at http://www.banglajol.info/index.php/CERB

* To whom all correspondence should be addressed.

(email: naima_khleifia@yahoo.fr) 


\section{INTRODUCTION}

The growing worldwide energy demand associated with several inter related complex environmental as well as economical issues are driving the increase of the share of uranium in energy mix. Subsequently, over the last few years, the interest for uranium extraction and recovery has increased [1]. Despite, the set back in the electronuclear industry because of the Japan Tsunami related crisis in march 2011 and its aftershock propagation particularly in Germany and many other countries, the demand for nuclear energy does not seem to lean. This is demonstrated by the increasing planned electronuclear production capacity in the coming decades.

Uranium is known to occur in phosphates with concentration ranging from 50-200 ppm [2-4]. During the production of phosphoric acid by the wet process, the phosphate mineral reacts with a mineral acid, generally sulfuric acid. Most of the uranium contained in the raw material passes into the phosphoric acid in the form of U(IV) and U(VI) ions [2]. The potential for uranium recovery from the wet process phosphoric acid (WPA) is substantial when large amounts of phosphate rock are processed. The separation of uranium from WPA has gained considerable importance. It is practiced for two main reasons: to produce uranium as a by-product and to prevent the contamination of soil by the radionuclide elements and rare earth metals through fertilizers.

Solvent extraction has been found to be a successful process for industrial recovery of uranium from phosphates, although other methods such as ion-exchange [5], membrane separation [6] and precipitation [7] have been investigated.
Uranium recovery from WPA using solvent extraction involves these steps: (i) phosphoric acid pre- treatment, (ii) uranium extraction, (iii) uranium purification by reextraction, (iv) product recovery, and (v) post - treatment of uranium depleted acid [2]. Most of these steps are liquid-liquid extraction operations. Because of the complexity of such operations, the choice of the best operating conditions has been a challenging task for engineers.

In the present work, the simulation of the uranium extraction from WPA in continuous counter current extraction column is conducted. The simulation is based on a fundamental model that integrates the material conservation equations with the mass transfer kinetics data obtained from experimental study. The developed computer code allows to obtain the concentration profiles of uranium along the extraction column. The influence of the extraction rate on the extraction performance is studied.

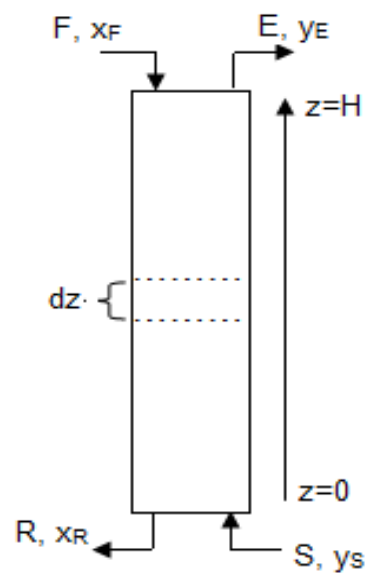

Figure 1: Schematic Representation of Extraction Column

\section{MODELING}

In this work, modeling of the uranium extraction is based on material conservation equations on the extraction column. Figure 1 describes a continuous counter current 
extraction column. The uranium content $x_{F}$ in feed flow rate $F$ is extracted with an organic solvent countercurrent feed flow rate of $\mathrm{S}$ with a uranium content of ys. The WPA is brought into contact with the solvent to lead to a raffinate $\mathrm{R}$ having a residual uranium content of $x_{R}$. The extract, designed by $\mathrm{E}$, leaves with uranium content $\mathrm{y}_{\mathrm{E}}$. The column extraction is supposed to be of a height $\mathrm{H}$ and a cross section $\mathrm{A}$.

The mathematical model for a liquidliquid extraction column relies on the following main assumptions [8-9]:

- Steady state

- Temperature is constant

- Axial as well as radial dispersions were neglected

- Mass transfer coefficient and the interfacial area are considered constant along the extraction column

An overall mass balance for volume element $\mathrm{dv}$ corresponding to a column height $\mathrm{dz}(\mathrm{dv}=\mathrm{A} . \mathrm{dz})$ yields the following equation:

$\left.R\right|_{z+d z}+\left.E\right|_{z}=\left.R\right|_{z}+\left.E\right|_{z+d z}$

Hence,

$\frac{d R}{d z}=\frac{d E}{d z}$

An overall mass balance on the aqueous phases for volume $\mathrm{dv}$ yields:

$\underbrace{\left.R\right|_{z+d z}}_{\text {input }}-\underbrace{\left.R\right|_{z}}_{\text {output }}=\underbrace{A \cdot d z \cdot k_{c} a \cdot\left(y^{*}(x)-y\right)}_{\text {Transferred quantity of uranium }}$

With $k_{c} a$ : The average product of the mass transfer coefficient relative to the continuous organic phase $\left(\mathrm{k}_{\mathrm{c}}\right)$ and the specific interfacial area (a). $y^{*}(x)-y:$ The mass transfer potential defined by the difference between the equilibrium, $y^{*}$, and the actual uranium content of the extract $y$.

The product of the mass transfer coefficient relative to the continuous organic phase $(\mathrm{kc})$ and the specific interfacial area (a) has been determinate in a pilot unit experiment [8]. The solute mass transfer driving force can be obtained from the equilibrium data determined in a separate experimental investigation.

Equation (3) can be expressed as:

$$
\frac{d R}{d z}=A \cdot k_{c} a \cdot\left(y^{*}(x)-y\right)
$$

An overall mass balance on the uranium in the aqueous phases for volume $d v$ yields

$$
\underbrace{\left.R x\right|_{z+d z}}_{\text {input }}-\underbrace{\left.R x\right|_{z}}_{\text {output }}=\underbrace{A \cdot k_{c} a \cdot d z \cdot\left(y^{*}(x)-y\right)}_{\text {Transfered quantity of uranium }}
$$

Combining the equation (4) in (5), the following equation (6) can be deduced.

$$
\frac{d x}{d z}=\frac{A \cdot k_{c} a \cdot\left(y^{*}(x)-y\right)}{R}(1-x)
$$

An overall mass balance on the uranium in the organic phases for volume $\mathrm{dv}$ gives:

$$
\underbrace{\left.E y\right|_{z}}_{\text {input }}+\underbrace{A \cdot k_{c} a \cdot d z \cdot\left(y^{*}(x)-y\right)}_{\text {Transfered quantity of uranium }}=\underbrace{\left.E y\right|_{z+d z}}_{\text {output }}
$$

After developing, the equation (7) reduces to:

$$
\frac{d y}{d z}=\frac{A \cdot k_{c} a \cdot\left(y^{*}(x)-y\right)}{E}(1-y)
$$

The equations (2), (4), (6) and (8) provide the $1^{\text {st }}$ order differential system defined by: 


$$
\left\{\begin{array}{l}
\frac{d x}{d z}=\frac{A \cdot k_{C} a \cdot\left(y^{*}(x)-y\right)}{R}(1-x) \\
\frac{d y}{d z}=\frac{A \cdot k_{C} a \cdot\left(y^{*}(x)-y\right)}{E}(1-y) \\
\frac{d R}{d z}=A \cdot k_{C} a \cdot\left(y^{*}(x)-y\right) \\
\frac{d E}{d z}=\frac{d R}{d z}
\end{array}\right.
$$

The differential problem has to be solved with the following initial and boundary conditions:

$$
\left\{\begin{array}{l}
\text { for } \mathrm{z}=0, x=x_{R}, y=y_{S} \\
\text { for } \mathrm{z}=H, x=x_{F}
\end{array}\right.
$$

A computer code has been developed for solving the obtained set of differential equations for any given operating conditions, i.e. WPA quality $\mathrm{x}_{\mathrm{F}}$, raffinate uranium content $x_{R}$ and column height $(H)$. Because, the problem combines initial as well as boundary conditions an iterative technique has been implemented to solve the numerical problem.

\section{RESULTS AND DISCUSSION}

\section{Uranium Concentration Profiles}

The computer code has been implemented to simulate the uranium extraction using Octyl Phenyl Phosphoric Acid (OPPA) diluted in kerosene as extractant. In order to simulate the uranium extraction by OPPA, the equilibrium data are needed. The partition curve has been approximated from experimental investigation and translated into an equation that gives the uranium partition ratio between the raffinate and extract phases [8].
A computer code that simulates the extraction operation was implemented. This code gives the concentration profiles and the amount of uranium transferred to the extract for a given operating conditions. A typical result for a solvent rate of 0.5 and uranium content in the feed acid $x_{F}=98 \mathrm{ppm}$ is reported. Figure 2 gives the uranium concentration profiles in both phases along the extraction column. In the same figure, the driving force of solute transfer, expressed in terms of the difference between the equilibrium and the actual uranium content of the extract is reported. As a result of the decreases of the driving, much of the mass transfer occurs close to the WPA inlet zone, i.e. top of the extraction column $\left(\mathrm{z}^{*}\right.$ close to 1). Indeed the mass transfer potential decreases by about $86 \%$ from the top to the bottom of the column. That is, the computer code provides valuable information on the intensity of solute transfer taking place along the column.

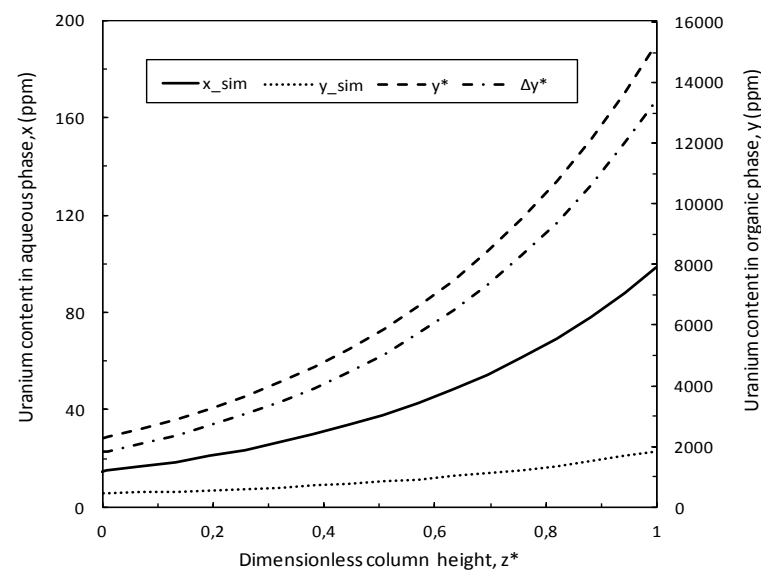

Figure 2: Uranium Concentration Profiles along Liquid-Liquid Extraction Column

The simulation results were confronted with those obtained experimentally. A relative good matching has been obtained as demonstrated in Figure 3. 


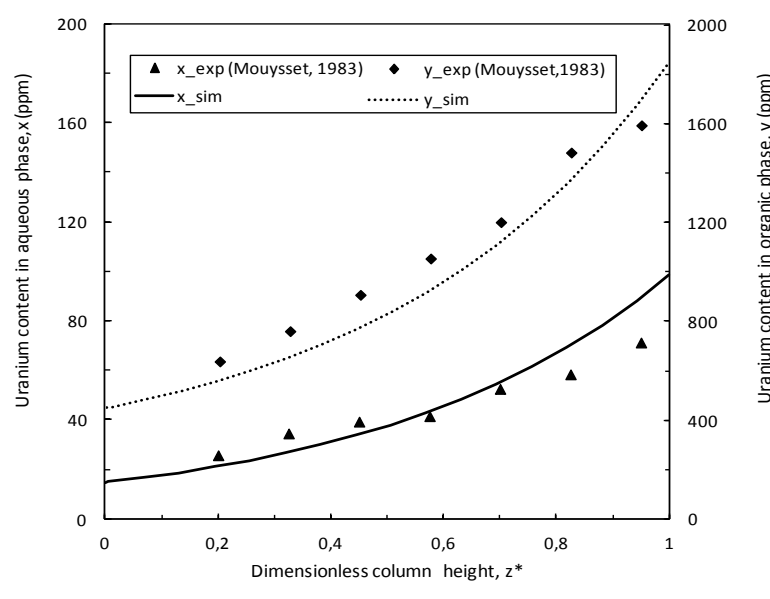

Figure 3: Simulation and Experimental Raffinate and Extract Uranium Content Profiles

\section{Effect of Solvent Rate}

Many parameters can affect the uranium extraction from WPA such as: initial concentration of phosphoric acid, temperature and solvent rate. In this work, simulations were carried out with optimal operating conditions obtained in experimental investigation $\left(\mathrm{T}=25^{\circ} \mathrm{C},\left[\mathrm{P}_{2} \mathrm{O}_{5}\right]\right.$ $=30 \%$ wt. $\mathrm{P}_{2} \mathrm{O}_{5} \quad$ ) [8].

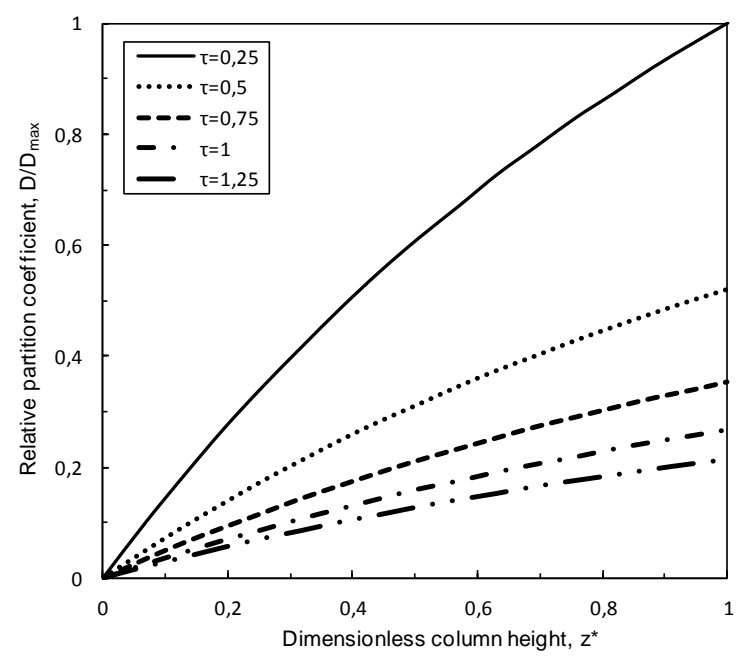

Figure 4: Uranium Partition Coefficient Evolution

The solvent rate is an important parameter of uranium extraction process. Hence it is necessary to consider the impact of this parameter on the uranium extraction performances. The computer code enables to study the effect of solvent rate on uranium distribution between the two phases of extraction.

The effect of varying the solvent rate is shown in Figure 4. When the solvent rate decreases the uranium concentration increases. That is, the solvent rate has to be carefully chosen to find a compromise between the uranium concentration in the extract and the solvent amount.

\section{Uranium Recovery Yield}

Uranium is recovered from phosphoric acid by the OPPA process in one extractionstripping cycle. The first operation consists of extracting uranium from phosphoric acid by OPPA. The loaded solvent is then stripped from uranium by hydrofluoric acid solution. These steps are liquid-liquid extraction operations.

The same computer code was used to predict the concentration profiles of uranium along the stripping column. The simulations provide several other valuable details such as extraction-stripping cycle yield evolution against operating parameters.

The extraction yield is defined as the ratio of extracted uranium amount and its initial quantity in the acid. The 3D representation of the uranium extractionstripping cycle yield as a function of solvent rate and stripping rate is given in Figure 5. According to this graph, for a given amount of solvent, the recovery yield increases with rising of stripping rate. The overall cycle yield is more important for small values of solvent rate and important values of stripping rate. The computer program could be used to predict extraction results for different operating conditions. The advantage of such investigation is to allow a better choice of the proper operating conditions for a desired uranium recovery extraction performance. The computer code could then be a useful tool for optimization 
purposes in the uranium recovery from wet process phosphoric acid.

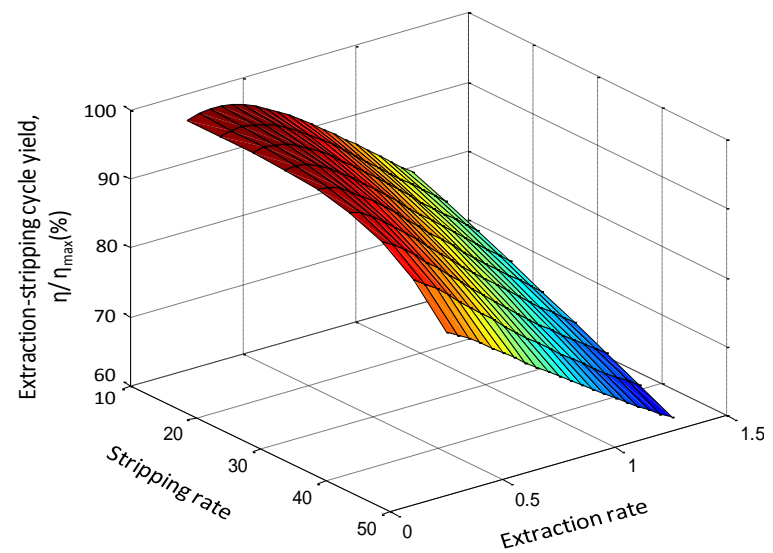

Figure 5: Extraction-Stripping Cycle Yield Evolution

\section{CONCLUSION}

In the present work, simulation of uranium extraction in continuous counter current extraction column was performed. Steady state material balances and equilibrium data was integrated to model the extraction process. A computer code has been developed to determine the uranium concentration profiles along extraction column and to investigate the effect of operating conditions. Thus, the developed computer code could be used as a tool for predicting the uranium extraction results in order to look for the optimal operating conditions.

\section{REFERENCES}

[1] Jean FF. dow process foruranium recovery from phosphoric acid, IAEA, Vienna, 4-6 $6^{\text {th }}, 2009$.

[2] Hurst FJ. Uranium from phosphoric acid, ORNL, Tennessee 37830, 1983.

[3] Botella T, Gasos P, Recovery of uranium from phosphoric acid: an overview. IAEA-Technical document 533, 1989.
[4] Magdi R, Mohammed K, Uranium fuel as byproduct fertilizer production, INREC 10, Jordan, 2010.

[5] Kabay N, Demiricioglu M, Yayh S, Gunay E and Yuksel M, Recovery of uranium from phosphoric acid solutions using chelating ionexchange resins. Industrial Engineering Chemical Research, 1998 (37): pp. 1983-1990.

[6] Joshi, JM.; Pathak, PN.; Pandey, AK.; Manchanda, VK. Study on synergistic carriers facilitated transport of uranium(VI) and europium(III) across supported liquid membrane from phosphoric acid media. Hydrometallurgy, 2009 (96):pp. 117-122.

[7] Weterings, K.; Jansen, J. Recovery of uranium, vanadium, yttrium and rare earths from phosphoric acid by a precipitation method. Hydrometallurgy, 1985 (15):pp. 173-190.

[8] Genevieve Mouysset, Jacques Molinier, Michel Lenzi; Utilization of discs and crowns pulsed column for extraction of uranium contained in phosphoric acid; Hydrometallurgy, 1983, 11.(2) :pp. 165-179.

[9] Molinier, J. Thesis of doctor engineer, University of Paul Sabatier, Toulouse, 1970.

Available online at http://www. Ganglajol.info/index.php/CERB 